\title{
Grid-connected control of PV-Wind hybrid energy system
}

\author{
Hakim Azoug ${ }^{1}$, Hocine Belmili², Fekkak Bouazza ${ }^{3}$ \\ ${ }^{1,3}$ Department of Electrical Engineering, University of Sciences and Technology Houari Boumediène, USTHB, Algeria \\ ${ }^{2}$ Unité de Développement des Équipements Solaires, UDES, Centre de Développement des Énergies Renouvelables, \\ CDER, 42415, Tipaza, Algérie
}

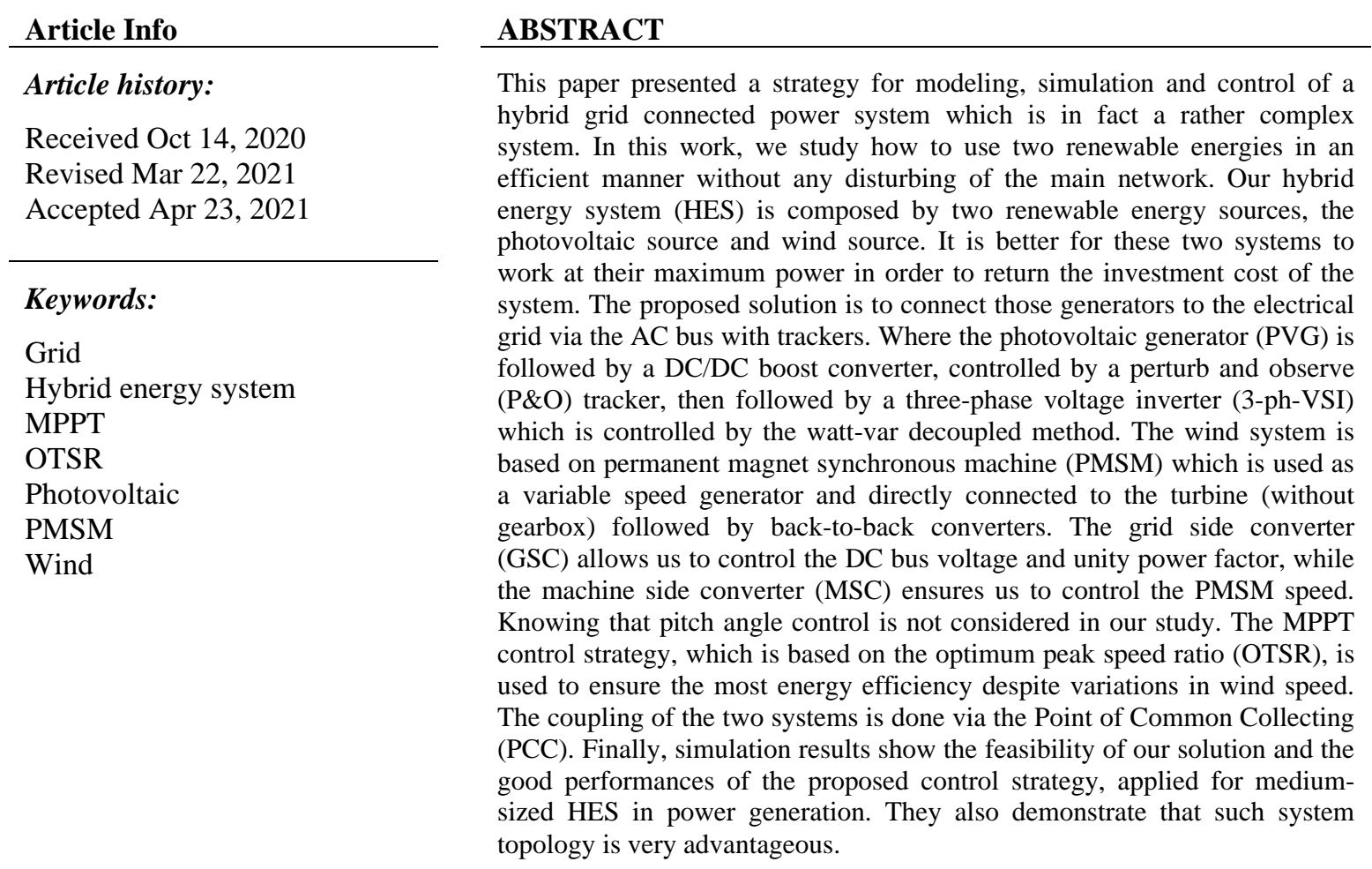

This is an open access article under the CC BY-SA license.

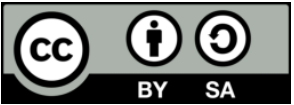

\section{Corresponding Author:}

Hocine Belmili

Unité de Développement des Équipements Solaires, UDES

Centre de Développement des Énergies Renouvelables, CDER, 42415, Tipaza, Algérie

Email: belmilih@yahoo.fr

\section{INTRODUCTION}

Along with the crisis of the exhaustion of the traditional energy resources, and with environmental damage caused by increased carbon dioxide emissions, the use of the renewable energy has become more and more one of the faster growing and clean energy resources [1]-[3]. Wind and photovoltaic energy sources can be considered as the most promising technologies for generating electricity [4]. However, solar irradiation and wind are intermittent and highly dependent on climatic conditions [5].

Hybrid energy system (HES) combines renewable and conventional energy sources. However, for the applications of autonomous SEHs, storage is essential when the grid is missing or when it is necessary to ensure continuity of service [3]-[6] which becomes an economic constraint. However, a possible connection 
to the grid would lead to minimize the requirement of the storage system [7], [8]. HES is advantageous in view of the reduction of the overall cost of the system, the response to the demand of the AC loads [9] and also the demand of the load of the network is relieved. HES systems cause problems when it is connected to the network. The first is maximise the power delivered by controllers depending of climatic or load variations [10], and synchronization with the power grid [11]. The proposed solution is to connect HES to the network via the $\mathrm{AC}$ bus with trackers.

Our studied HES system is characterized by two energy sources without a storage system in order to minimize the cost of the system. These two energy sources will be coupled to the electricity network via the $\mathrm{AC}$ bus. As shown in Figure 1, the photovoltaic generator (PVG) is followed by a DC/DC converter; the latter will be controlled by the Perturb and Observe (P\&O) algorithm, it is a technique to control MPPT (Maximum Power Point Tracking) where many researchers have focus on the implementation of this method [12], followed by a three-phase inverter (3-ph VSI) controlled by the decoupled Whatt-Var approach to be able to control the active and reactive powers that we need to inject to the grid. Two back-to-back converters power are used for the wind system energy. It is composed of a PMSG, its control strategy is used for the GSC to realize the decoupled current control concept to control active and reactive power and to maintain a constant DC bus voltage [13], [14]. The Field Oriented Control (FOC) is used by the MSC to control the speed of the PMSG [15].

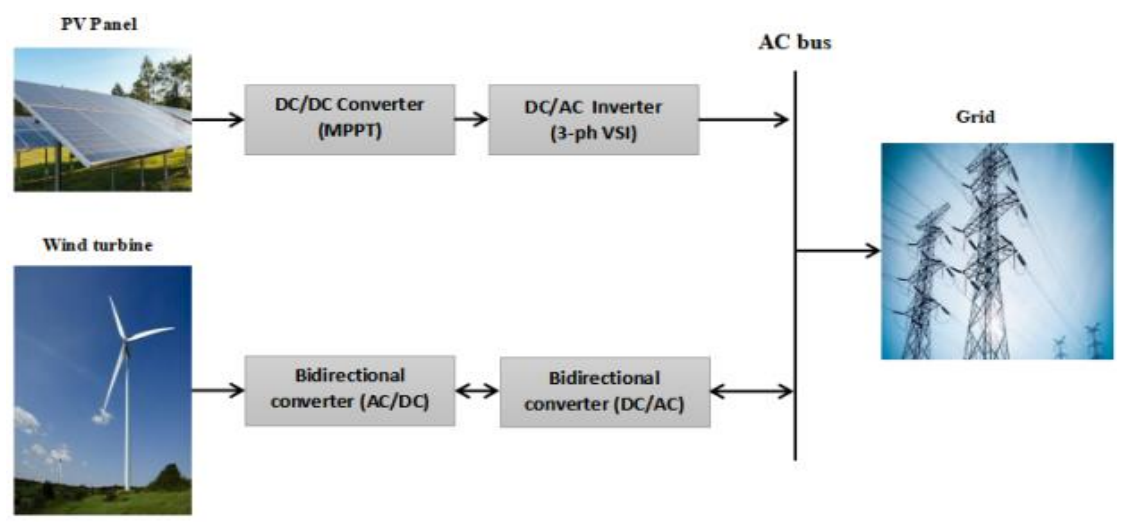

Figure 1. Proposed configuration of grid connected HES (PV/Wind)

We subdivided our work into three parts, where we will present the analysis, modeling and control of the grid connected PV system, the grid connected wind system and the grid connected PV/Wind system. we finalize it by giving the result of simulation of our system under MATLAB/Simulink, a discussion of the results obtained and a conclusion.

\section{GRID CONNECTED PV/ WIND SYSTEM}

\subsection{Grid conected $P V$ system}

Grid connected PV system studied shown in figure 2 is composed by photovoltaic modules (KC200GT modules which is tested and well suited to traditional photovoltaic applications [16]), MPPT controller, boost converter, three-phase Inverter (We choose those without transformer due to its high efficiency and low cost [17]), output self-filter and finally a circuit breaker to connect our system to the power grid [18].

The PV generator generates a DC voltage, so it is necessary to use an inverter to convert DC voltage into an alternative voltage (AC) [9]. In our study, a three-phase bidirectional DC/AC inverter was done by the decoupled Whatt-Var approach. This approach purpose is to control the active power $(\mathrm{P})$ and the reactive power (Q). At Common Coupling Point (CCP), we measured the three-phase Voltages $\left(\mathrm{V}_{\mathrm{abc}}\right)$ [19], [20]. From the voltage control loop, witch is considered to control the voltage of the DC side [8], we have :

$\left[\begin{array}{l}\mathrm{u}_{\mathrm{a}} \\ \mathrm{u}_{\mathrm{b}} \\ \mathrm{u}_{\mathrm{c}}\end{array}\right]=\left[\begin{array}{l}\mathrm{v}_{\mathrm{a}} \\ \mathrm{v}_{\mathrm{b}} \\ \mathrm{v}_{\mathrm{c}}\end{array}\right]-\mathrm{L} \frac{\mathrm{d}}{\mathrm{dt}}\left[\begin{array}{c}\mathrm{i}_{\mathrm{a}} \\ \mathrm{i}_{\mathrm{b}} \\ \mathrm{i}_{\mathrm{c}}\end{array}\right]$

Applying Park's transformation method, (1) can be rewritten as follow [18], [21], [22]: 


$$
\left\{\begin{array}{l}
u_{d}=v_{d}-L \frac{d i_{d}}{d t}+\omega_{0} \cdot L \cdot i_{q} \\
u_{q}=v_{q}-L \frac{d i_{q}}{d t}-\omega_{0} \cdot L \cdot i_{d}
\end{array}\right.
$$

The $\mathrm{d}-\mathrm{q}$ control is considered for transformation of $\mathrm{V}_{\mathrm{a}, \mathrm{b}, \mathrm{c}}$ known as grid voltages. It can be deduced:

$$
\left\{\begin{array}{l}
u_{d}=v_{d}-K_{p}\left(1+\frac{K_{i}}{s}\right)\left(i_{d r e f}-i_{d}\right)+\omega_{0} L i_{q} \\
u_{q}=v_{q}-K_{p}\left(1+\frac{K_{i}}{s}\right)\left(i_{q r e f}-i_{q}\right)-\omega_{0} L i_{d}
\end{array}\right.
$$

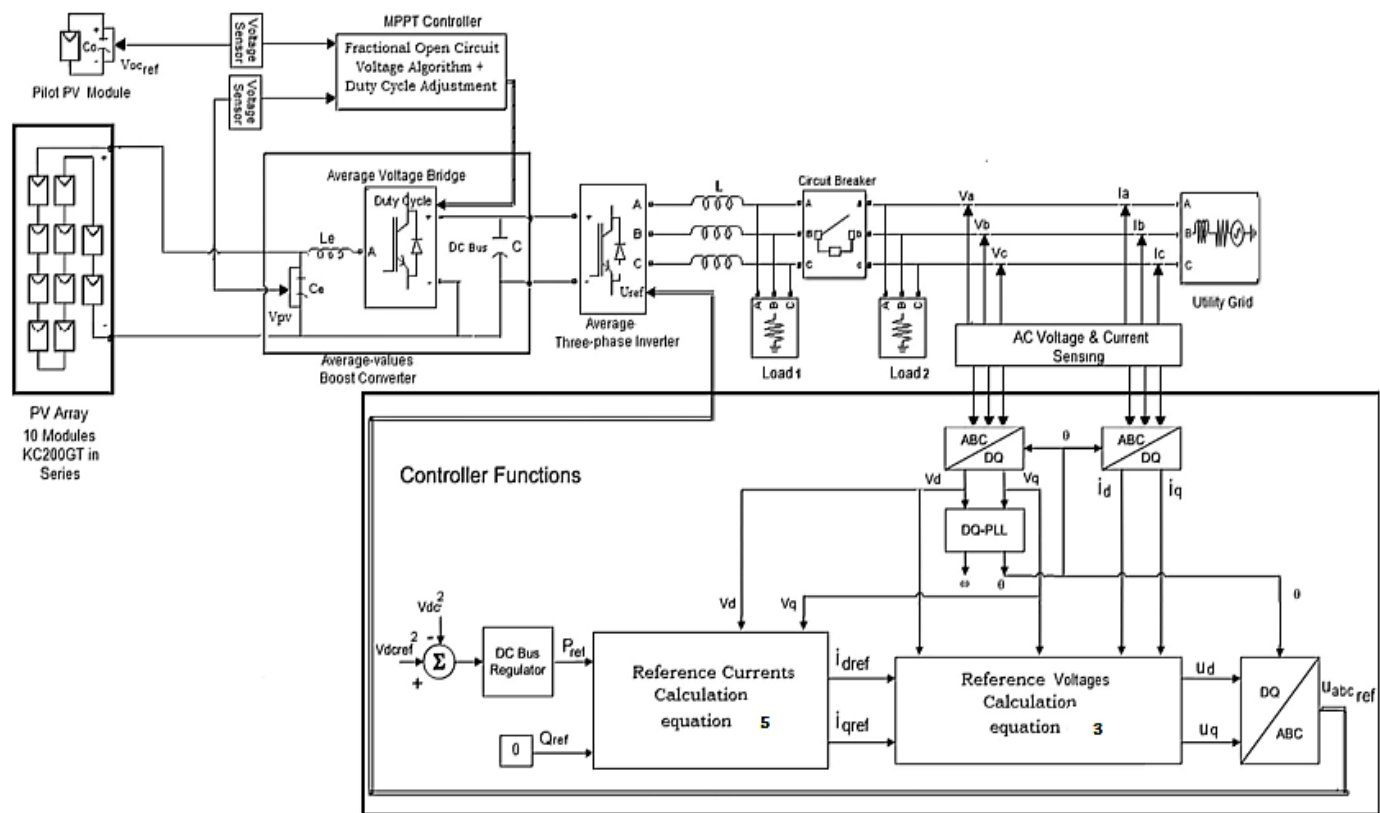

Figure 2. Main diagram of the PV system connected to the main Grid

Errors in system parameters must be compensated by the PI regulator. To control active and reactive power, we use the decoupled Watt-Var control [18], [23].

The active and reactive powers are expressed in (4) [18, 24]:

$$
\left\{\begin{array}{l}
\mathrm{P}=\frac{3}{2} *\left(\mathrm{v}_{\mathrm{d}} * \mathrm{i}_{\mathrm{d}}+\mathrm{v}_{\mathrm{q}} * \mathrm{i}_{\mathrm{q}}\right) \\
\mathrm{Q}=\frac{3}{2} *\left(\mathrm{v}_{\mathrm{q}} * \mathrm{i}_{\mathrm{d}}-\mathrm{v}_{\mathrm{d}} * \mathrm{i}_{\mathrm{q}}\right)
\end{array}\right.
$$

The currents references ( $i_{\text {dref }}, i_{\text {qref }}$ ) can be expressed by (5):

$$
\left[\begin{array}{l}
\mathrm{i}_{\mathrm{q}} \mathrm{irf} \\
\mathrm{i}_{\mathrm{dref}}
\end{array}\right]=\frac{2}{3\left(\mathrm{v}_{\mathrm{d}}{ }^{2}+\mathrm{v}_{\mathrm{q}}{ }^{2}\right)}\left[\begin{array}{cc}
\mathrm{v}_{\mathrm{d}} & \mathrm{v}_{\mathrm{q}} \\
\mathrm{v}_{\mathrm{q}} & -\mathrm{v}_{\mathrm{d}}
\end{array}\right]\left[\begin{array}{l}
\mathrm{P}_{\text {ref }} \\
\mathrm{Q}_{\text {ref }}
\end{array}\right]
$$

This decoupled Watt-Var control strategy allows the inverter to supply all the power generated by the photovoltaic module to the network and it also serves to control the DC bus voltage [11].

\subsection{Grid conected wind system}

The study wind energy conversion system is connected to the grid. The PMSG provides the power to the grid through back-to-back power converters and filter as illustrated in Figure 4 [25] 


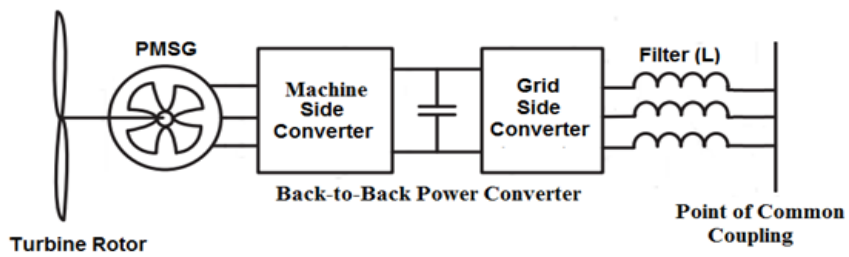

Figure 4. PMSG based wind energy conversion system [25]

\subsubsection{Wind turbine modeling}

The modeling of wind turbine helps to understand the dynamic and static behaviour of the wind system. The power output of wind turbine $\mathrm{P}_{t}(\mathrm{~W})$ is given by [26]:

$$
P_{t}=\frac{1}{2} \rho \pi \mathrm{R}^{2} \mathrm{C}_{P}(\lambda, \beta) \mathrm{V}_{v}^{3}
$$

The tip speed ratio $(\lambda)$ and the power coefficient $\left(C_{p}\right)$ can be expressed as follows (7)-(9):

$\lambda=\frac{\omega_{m} \cdot R}{v}$

$C_{p}(\lambda)=0.5176\left(\frac{116}{\lambda_{i}}-5\right) \cdot \exp ^{\frac{21}{\lambda_{i}}}+0.006795 \lambda_{i}$

$\lambda_{i}=\frac{1}{\frac{1}{\lambda}-0.035}$

Further, the Mechanical torque $\left(\mathrm{T}_{\mathrm{t}}\right)$ presented in equation12, can be deduced form (6):

$$
T_{t}=\frac{P_{t}}{\omega_{m}}=\frac{1}{2 \lambda} \cdot \rho \cdot \pi \cdot R^{3} \cdot v^{2} \cdot C_{p}(\lambda)
$$

Aerodynamic torque coefficient $\left(C_{t}(\lambda)\right)$ is determined by $(11)$ :

$C_{t}(\lambda)=\frac{C_{p}(\lambda)}{\lambda}$

Form equations (10) and (11), $\left(\mathrm{T}_{\mathrm{t}}\right)$ can be rewritten as follow (12):

$$
T_{t}=0.5 \cdot \rho \cdot \pi \cdot R^{3} \cdot v^{2} \cdot C_{t}(\lambda)
$$

Figure 5 and Figure 6 illustrated respectively the Wind turbine power-speed and $C_{t}(\lambda)$ characteristics for the study wind turbine.

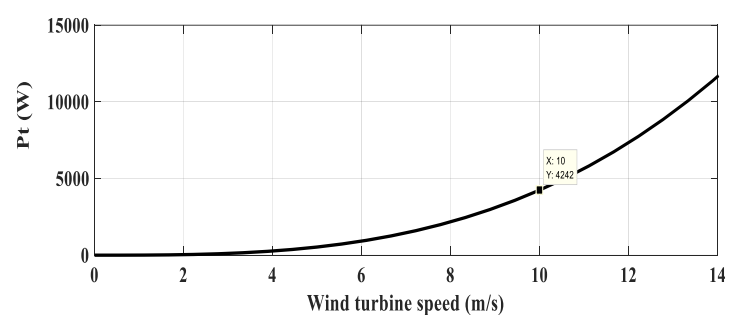

Figure 5. Wind turbine power-speed characteristic

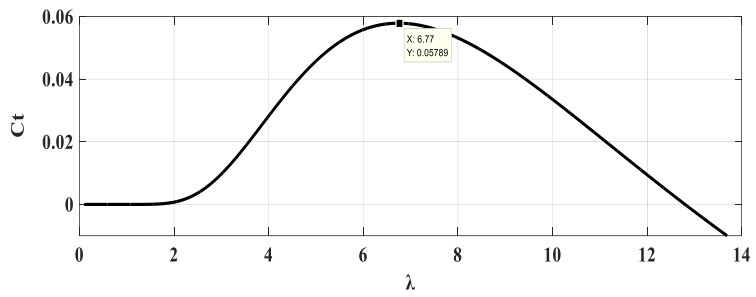

Figure 6. $\mathrm{Ct}(\lambda)$ characteristic

\subsubsection{Modeling of the permanent magnet synchronous generator (PMSG)}

For a simpler and easier analysis: The stator windings are connected in Y; losses by hysteresis and eddy current are neglected and no dynamic response process of the excitation current [27]:

Electrical equation of PMSG is expressed below: 
$v_{a b c_{s}}=\frac{d \psi_{a b c_{s}}}{d t}+R_{s} i_{a b c_{s}}$

Applying Park transform equation (13) becomes:

$\left[\begin{array}{l}v_{d_{s}} \\ v_{q_{s}}\end{array}\right]=\left[P\left(\theta_{m}\right)\right]\left[R_{s}\right]\left[P\left(\theta_{m}\right)\right]^{-1} i_{d q_{s}}+\left[P\left(\theta_{m}\right)\right]\left[P\left(\theta_{m}\right)\right]^{-1} \frac{d}{d t}\left[\psi_{d q_{s}}\right]+\left[P\left(\theta_{m}\right)\right]\left(\frac{d}{d t}\left[P\left(\theta_{m}\right)\right]^{-1}\right)\left[\psi_{d q_{s}}\right]$

Where $P\left(\theta_{m}\right)$ is park transformation expressed as follow:

$$
\begin{aligned}
& P\left(\theta_{m}\right)=\frac{2}{3}\left[\begin{array}{l}
\cos \left(\theta_{m}\right) \cos \left(\theta_{m}-\frac{2 \pi}{3}\right) \cos \left(\theta_{m}+\frac{2 \pi}{3}\right) \\
-\sin \left(\theta_{m}\right)-\sin \left(\theta_{m}-\frac{2 \pi}{3}\right)-\sin \left(\theta_{m}+\frac{2 \pi}{3}\right) \\
\frac{1}{2} \frac{1}{2} \frac{1}{2}
\end{array}\right] \\
& {\left[\psi_{d q_{s}}\right]=\left[\begin{array}{l}
\psi_{d_{s}} \\
\psi_{q_{s}}
\end{array}\right]=\left[\begin{array}{l}
L_{d} \\
0 \\
0 L_{q}
\end{array}\right]\left[\begin{array}{l}
i_{d_{s}} \\
i_{q_{s}}
\end{array}\right]\left[\begin{array}{l}
\psi_{f} \\
0
\end{array}\right]}
\end{aligned}
$$

On other hand and as is expressed in (17):

$$
\begin{aligned}
& {\left[P\left(\theta_{m}\right)\right]\left[P\left(\theta_{m}\right)\right]^{-1} \frac{d}{d t}\left[\psi_{d q_{s}}\right]=\frac{d}{d t}\left(\theta_{m}\right) \cdot P\left(\frac{\pi}{2} \cdot\left[\psi_{d q_{s}}\right]=\omega_{s}\left[\psi_{d q_{s}}\right]^{\prime}\right)} \\
& \left\{\begin{array}{c}
v_{d_{s}}=-\omega_{s} \cdot \psi_{q_{s}}+\left(R_{s}+p L_{d}\right) i_{d_{s}} \\
v_{q_{s}}=\omega_{s} \cdot \psi_{d_{s}}+\left(R_{s}+p L_{q}\right) i_{q_{s}}
\end{array}\right.
\end{aligned}
$$

Where:

$\omega_{s}=n_{p} \cdot \omega_{m}$

Substituting (16) in (18), we obtain:

$\left\{\begin{array}{c}v_{d_{s}}=L_{q_{s}} i_{q_{s}}-\omega_{s} \cdot\left(R_{s}+p L_{d}\right) i_{d_{s}} \\ v_{q_{s}}=\omega_{s} . L_{d_{s}} i_{d_{s}}+\left(R_{s}+p L_{q}\right) i_{q_{s}}+E_{s}\end{array}\right.$

The mathematical relationship of electromagnetic torque in the $\mathrm{d}-\mathrm{q}$ axis is expressed by :

$T_{e}=\frac{3}{2} n_{p}\left[\psi_{d} i_{q_{s}}+\left(L_{d}-L_{q}\right) i_{d_{s}} i_{q_{s}}\right]$

The expression of (21) can be reduced to (22) by putting $i_{d_{s}}=0$ :

$T_{e}=\frac{3}{2} n_{p} \psi_{f} i_{q_{s}}$

\subsubsection{Machine side converter (MSC) control strategy}

To adjust the PMSG torque, the rotation speed is controlled to follow the maximum power while the wind speed changes $[13,15]$ and this is done by the MSC control. This strategy is based on a double closed loop control (Current and speed control) [28]. In the analysis presented in the following, we will use the OTSR. From Figure 6, we have $C_{t}(\lambda)$ is maximal for optimum values of $\left(\boldsymbol{\lambda}_{\text {opt }}\right)$ and $\omega_{m}{ }^{*}$ can be expressed as:

$$
\omega_{m}^{*}=\frac{\lambda_{o p t} \cdot v}{R}
$$

According to our system, the current inner loop control for the direct and quadrature components has the same dynamics to utilize the fast response. The PI controller regulates error results [29].

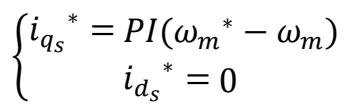


The two voltages $\left(v_{d_{s}}{ }^{*}\right)$ and $\left(v_{q_{s}}{ }^{*}\right)$ which are described in (20), are calculated as below:

$$
\left\{\begin{array}{l}
v_{q_{s}}{ }^{*}=P I\left(i_{q_{s}}{ }^{*}-i_{q_{s}}\right) \\
v_{d_{s}}{ }^{*}=\operatorname{PI}\left(i_{d_{s}}{ }^{*}-i_{d_{s}}\right)
\end{array}\right.
$$

To control the MSC, from (20) we have the modulating signal $\left(u_{a b c_{s}}{ }^{*}\right)$ :

$$
u_{a b c_{s}}{ }^{*}=\left[P\left(\theta_{m}\right)\right]^{-1} \boldsymbol{X} u_{d q_{x}}{ }^{*}
$$

\subsubsection{PI regulators synthesis}

To simplify controller design, th PI controller is analyzed in the synchronous d-q frame. The torque control strategy adopted in many studies uses two separate current regulators for ids and $\mathrm{i}_{\mathrm{qs}}$ [30]. In other hand; after compensation, (16) becomes:

$$
\left\{\begin{array}{l}
v_{d_{s}}=L_{d} \frac{d i_{d_{s}}}{d t}+R_{s} i_{d_{s}} \\
v_{q_{s}}=L_{q} \frac{d i_{q_{s}}}{d t}+R_{s} i_{q_{s}}
\end{array}\right.
$$

According to (27), we have $[13,21]$ :

$$
\begin{aligned}
\frac{i_{q_{s}}}{v_{q_{s}}} & =\frac{1}{s L_{q}+R_{S}} \\
\frac{i_{d_{S}}}{v_{d_{s}}} & =\frac{1}{s L_{d}+R_{s}}
\end{aligned}
$$

Figure 7 represents the MSC control bloc diagram where there are two similar PI regulators which controls the direct and quadrature components.

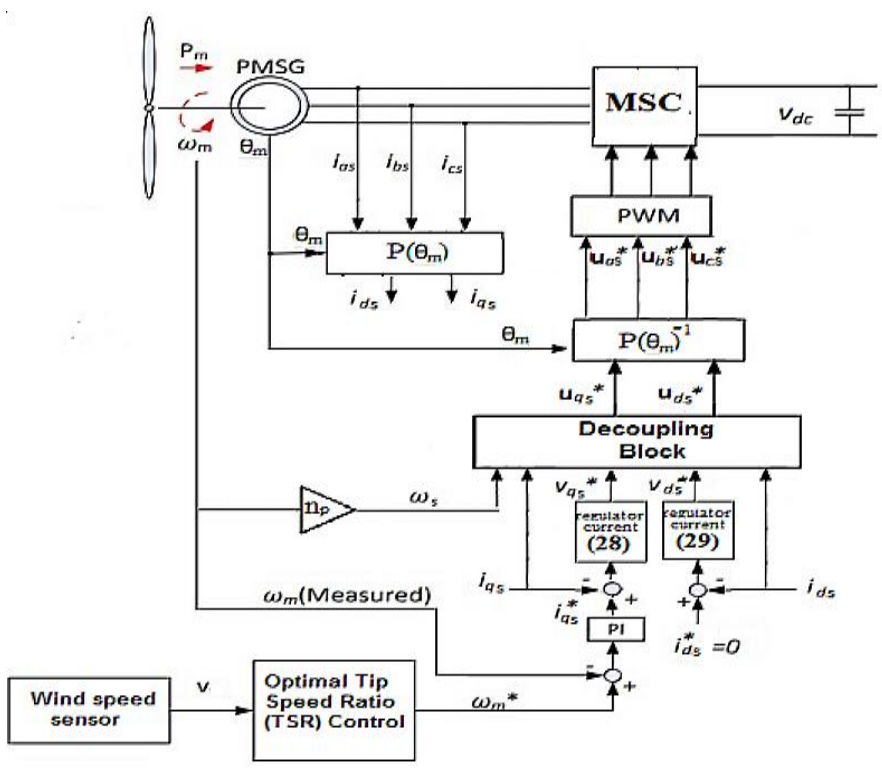

Figure 7. MSC control block diagram

\subsubsection{GSC control using resonant controller}

The objective of the GSC is to maintain the continuous bus voltage constant and to control the active and reactive power to be injected into the network [31]. In this method, the direct park transform is not used. From Figure 7, we obtain: 


$$
\left\{\begin{array}{c}
i_{g}{ }^{*}=P I \cdot\left(v_{d c}^{*}-v_{d c}\right) \\
i_{d_{g}}^{*}=0
\end{array}\right.
$$

Applying Inverse Park transform, the grid currents references in 'abc' coordinate, $\left(i_{a b c_{g}}{ }^{*}\right)$ are deduced in (31)

$$
\begin{aligned}
& i_{a b c_{g}}{ }^{*}=\left[P\left(\theta_{g}\right)\right]^{-1} X i_{d q_{g}}{ }^{*} \\
& v_{a b c_{i}}{ }^{*}=\left(i_{a b c_{g}}{ }^{*} i_{a b c_{g}}\right)\left(k_{p}+k_{i} \cdot \frac{2 s}{s^{2}+\omega^{2}}\right)
\end{aligned}
$$

We have to point out, that with this method the problem of the coupling term is not posed.

\section{RESULTS AND DISCUSSION}

The simulation results under MATLAB/simulink is shown in Figure 8 to Figure 21. The simulation time of the system is set to $3 \mathrm{~s}$ with an abrupt wind speed profile in order to check the characteristics of the system in order to maintain stable operation.

Figure 11 shows that the PLL, successfully tracking the new network frequency as expected. The accuracy of the PLL in detecting the phase angle of the power grid is therefore demonstrated. The following simulation results are to be demonstrated if the change in frequency does not affect the behavior of the entire system.

The simulation of our hybrid SEH system is proposed; both systems (PV and wind) are connected to the network via the AC bus. In our study, we chose to inject all the active powers resulting from the production of photovoltaic and wind systems by fixing the reactive powers of the two zero systems.In addition, the simulation results of the SEH are virtually the same as for each system operating on its own. This is the strong point of this topology, that is to say in addition to the simplicity of the command, if one system at a given moment will fail, the other remains operational, which is not the case for the DC bus architecture. The Active and Reactive powers delivered by the wind and PV systems, which are injected into the electrical grid, was represented by Figure 15 and Figure 20 respectively. While all the resulting Active and Reactive powers of the PV and wind systems are injected into the electrical grid, was represented by Figure 21.

- From 1.8 to $2 \mathrm{~s}, \mathrm{G}=1000 \mathrm{w} / \mathrm{m}^{2}, \mathrm{~V}=13 \mathrm{~m} / \mathrm{s}, \mathrm{P}_{1 \mathrm{ref}}=9320 \mathrm{~W}, \mathrm{P}_{2 \mathrm{ref}}=2000 \mathrm{~W}, \mathrm{f}=50.2 \mathrm{~Hz}$ : The active powers to be delivered by the PV and wind systems are respectively $2000 \mathrm{~W}$ and $9320 \mathrm{~W}$.

- From 2 to $3 \mathrm{~s}, \mathrm{G}=1000 \mathrm{w} / \mathrm{m}^{2}, \mathrm{~V}=15 \mathrm{~m} / \mathrm{s}, \mathrm{P}_{1 \mathrm{ref}}=14320 \mathrm{~W}, \mathrm{P}_{2 \mathrm{ref}}=2000 \mathrm{~W}, \mathrm{f}=50 \mathrm{~Hz}$ : The active powers to be delivered by the PV and wind systems are respectively $2000 \mathrm{~W}$ and $9320 \mathrm{~W}$. According to Figure 21, regardless of the evolution of irradiation and wind speed, the reactive power injected into the network remains zero. This result confirms that the decoupled current control method is very precise in the PPM follow-up.

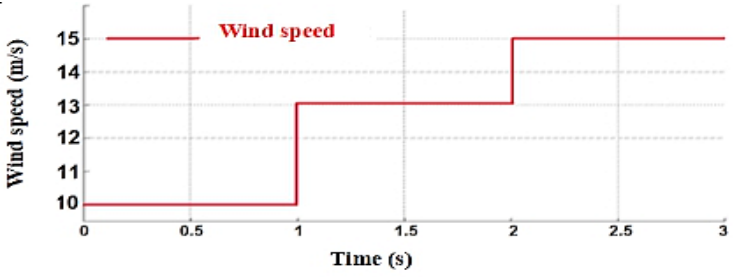

Figure 8. Wind speed profile

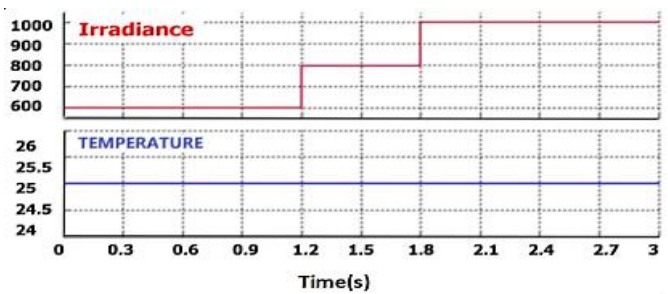

Figure 9. Solar irradiation and temperature profile 


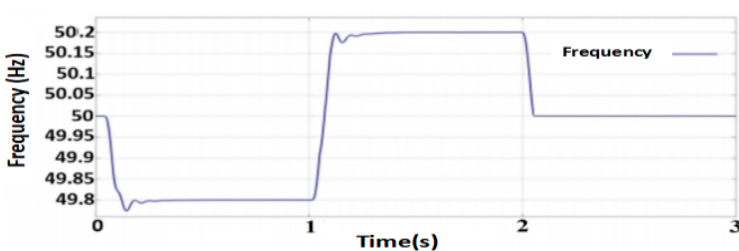

Figure 10. Network frequency detected by PLL

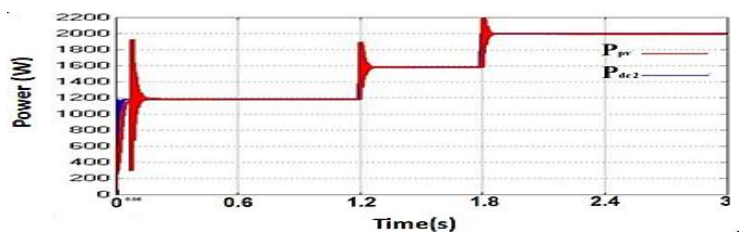

Figure 12. Power on DC side

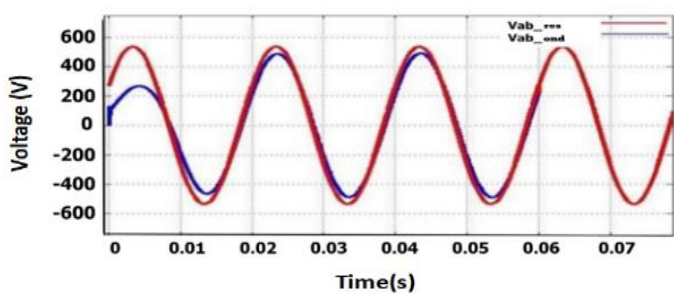

Figure 14. Network and inverter voltage $\left(\mathrm{V}_{\mathrm{ab} \_ \text {grid }} / \mathrm{V}_{\mathrm{ab} \_ \text {ond }}\right)$

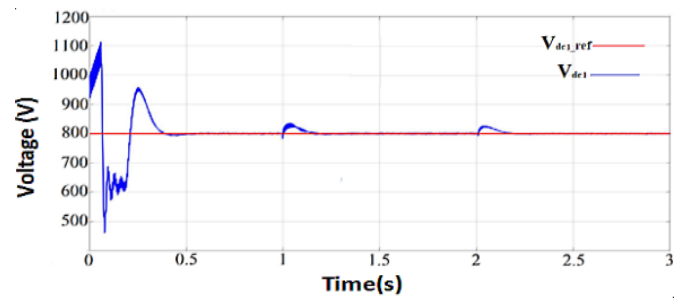

Figure 16. Reference voltage and continuous bus voltage of the wind system

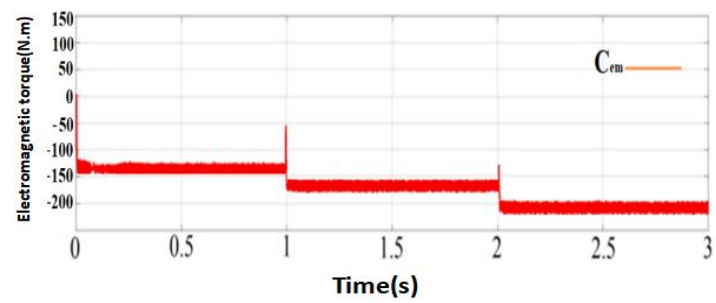

Figure 18. Electromagnetic torque $\left(\mathrm{C}_{\mathrm{em}}\right)$

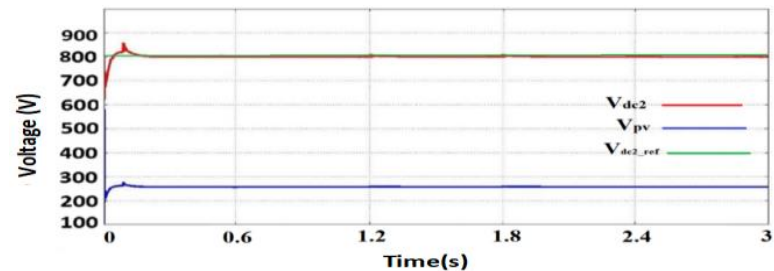

Figure 11. Voltage on DC side

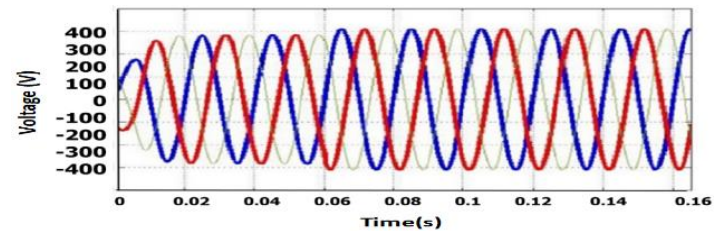

Figure 13. Inverter voltage $\left(\mathrm{V}_{\mathrm{abc} \_ \text {ond }}\right)$

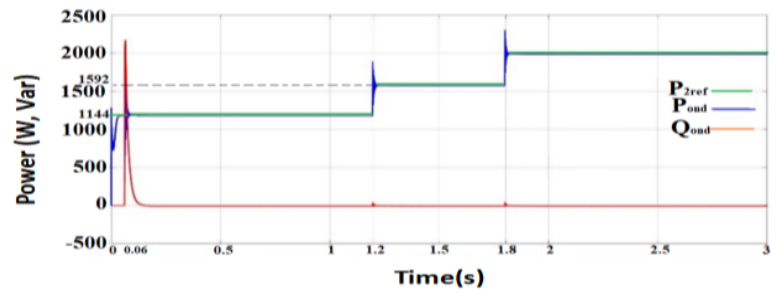

Figure 15. Active and reactive powers delivered by the $\mathrm{PV}$ inverter

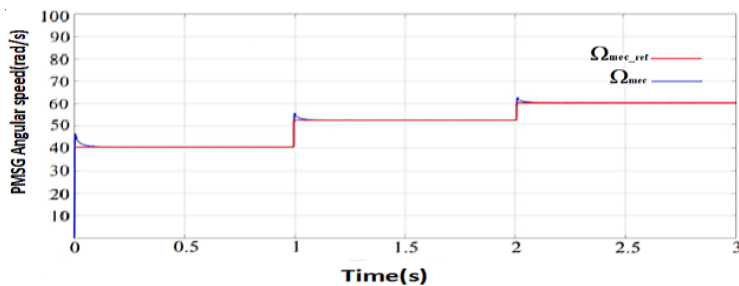

Figure 17. Reference Angular Speed and PMGS Rotor Angular Speed

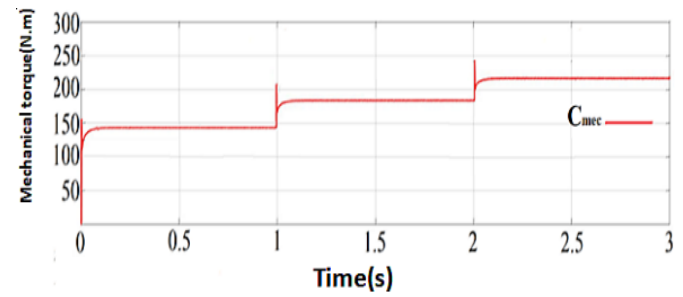

Figure 19. Mechanical torque $\left(\mathrm{C}_{\mathrm{mec}}\right)$ 


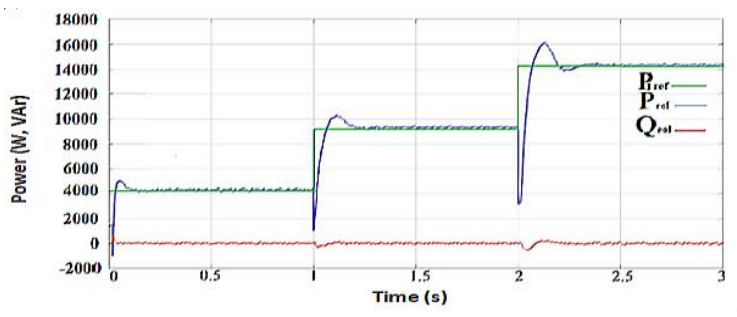

Figure 20. Active and Reactive Powers delivered by the wind system

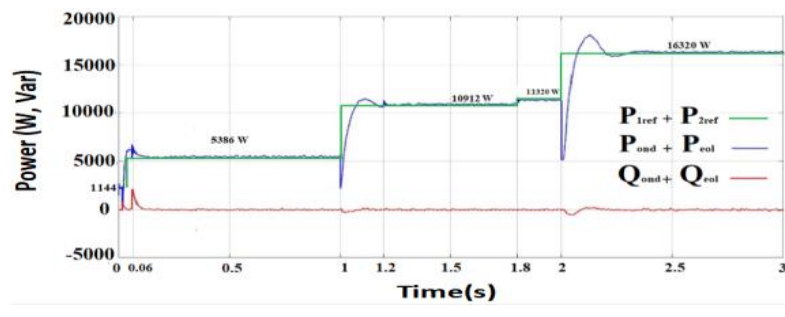

Figure 21.HES Active and Reactive Powers Injected into the Network

\section{CONCLUSION}

The present work concerns the most current application of renewable energies, that of the simulation and control of SEH connected to the electricity distribution network. Our study was limited to two systems: PV system and Wind system connected to the power grid via the PCC. Control strategies and simulation are presented. The grid-connected photovoltaic system without a transformer, without storage system, using a simple and easy to MPPT controller, can be considered a very interesting topology for such applications.

The simulation results show that the active powers produced by each of the two PV and wind systems are effectively added and injected into the network. The reactive power resulting from the reactive powers of both systems is maintained at zero, despite sudden variations in solar irradiation and wind speed. Although this AC Bus architecture is more expensive than the DC Bus architecture, the simplicity of ordering to be a relevant advantage for our choice. It shows also the correct tracking accuracy and fast response with MPPT technique. The PLL allows to extract the phase angle of the network with preview. By quickly synchronizing the PV system to the network.

The voltage of the continuous bus, which is a critical parameter for integrating such an energy system into the power grid, is kept constant. The results also show that the active output power is stable and that the wind turbine can operate with high efficiency as expected. Finally, the use of a resonant controller for the network-side converter (GSC) is advantageous, given the simplicity of its design and the speed of simulation. The performance of the power control of the SEH with injection of the entire production to the grid is conclusive with a good follow-up of the instructions and rejection of the disturbances, despite the sudden variations in frequency, irradiation and wind.

\section{REFERENCES}

[1] V. Khare, S. Nema, and P. Baredar, "Solar-wind hybrid renewable energy system," Renewable and Sustainable Energy Reviews, vol. 58, pp. 23-33, 2016, DOI: 10.1016/j.rser.2015.12.223.

[2] S. Henninger and J. Jaeger, "Advanced classification of converter control concepts for integration in electrical power systems," Electrical Power and Energy Systems, vol. 123, p. 106210, 2020, DOI: 10.1016/j.ijepes.2020.106210.

[3] M. Faisal, A. Hannan, P. Jern Ker, A. Hussain, M. Bin Mansor, and F. Blaabjerg, "Special Section On Advenced Energy Storage Technologies And Their Applications," Review of Energy Storage System Technologies in Microgrid Applications: Issues and Challenges, vol. 8, pp. 218685-218693, 2020, DOI: 10.1109/ACCESS.2020.3036556.

[4] Q. Hong, et al., "Design and Validation of a Wide Area Monitoring and Control System for Fast Frequency Response," IEEE Transactions on Smart Grid, vol. 11, no. 4, pp. 3394-3404, 2020, DOI: 10.1109/TSG.2019.2963796.

[5] F. Weschenfelder, et al., "A review on the complementarity between grid-connected solar and wind power systems," Journal of Cleaner Production, vol. 257, p. 120617, 2020, DOI: 10.1016/j.jclepro.2020.120617.

[6] V.D. Lazarov, G. Notton, Z. Zarkov, and I. Bochev, "Hybrid power systems with renewable energy sources types, structures, trends for research and development," In Proceedings of International Conference ELMA2005, 2005, pp. 515-520.

[7] M. E. Azzaoui, H. Mahmoudi and K. Boudaraia, "Backstepping control of wind and photovoltaichybrid renewable energy system," International Journal of Power Electronics and Drive Systems (IJPEDS), vol. 7, no. 3, pp. 677686, 2016, DOI: 10.11591/ijpeds.v7.i3.pp677-687.

[8] M. Pushpavalli, N. M Jothi Swaroopan, "Performance analysis of hybrid photovoltaic/wind energysystem using KY boost converter, " International Journal of Power Electronics and Drive System (IJPEDS), vol. 10, no. 1, pp. 433-443, 2019, DOI: 10.11591/ijpeds.v10.i1.pp433-443.

[9] A. Hota, S. K. Bhuyan, and P. K. Hota, "Modeling \& Simulation of Photovoltaic System Connected to Grid using MATLAB," 2020 International Conference on Renewable Energy Integration into Smart Grids: A 
Multidisciplinary Approach to Technology Modelling and Simulation (ICREISG), 2020, pp. 16-21, DOI: 10.1109/ICREISG49226.2020.9174192.

[10] T. K. Roy and M. A. Mahmud, "Active power control of three-phase grid-connected solar PV systems using a robust nonlinear adaptive backstepping approach," Solar Energy, vol. 153, pp. 64-76, 2017, DOI: 10.1016/j.solener.2017.04.044.

[11] W. Zahoor and S.H. Zaidi, "Synchronization and dq current control of grid-connected voltage source inverter. In Multi-Topic," 17th IEEE International Multi Topic Conference 2014, 2014, pp. 462-466, DOI: 10.1109/INMIC.2014.7097384.

[12] Z. Fei, D. Mingchang, and Z. Junjun, "Modelling and simulation of Grid-connected PV System in DIgSILENT/PowerFactory," 2nd IET Renewable Power Generation Conference (RPG 2013), 2013, pp. 1-6, DOI: 10.1049/cp.2013.1867.

[13] Uday B. Mujumdar and D.R. Tutakne, "PLL for Grid Synchronization of Single Phase Distributed Generation System," IOSR Journal of Electrical and Electronics Engineering (IOSR-JEEE), vol. 11, no. 5, pp 28-33, 2016, DOI: 10.9790/1676-1105032833.

[14] Y. Zhang, M.G.L. Roes, M.A.M. Hendrix, and J.L. Duarte, "Symmetric-component decoupled control of gridconnected inverters for voltage unbalance correction and harmonic compensation," Electrical Power and Energy Systems, vol. 115, p. 105490, 2020, DOI: 10.1016/j.ijepes.2019.105490.

[15] H. Joshi, A. K. Swami, and K. Matiyali, "Simulation and Modeling of a Wind Turbine using PMSG with Maximum Power Tracking Control," 2019 Women Institute of Technology Conference on Electrical and Computer Engineering (WITCON ECE), 2019, pp. 49-53, DOI: 10.1109/WITCONECE48374.2019.9092893.

[16] E. M. Salilih and Yilma T. Birhane, "Modeling and Analysis of Photo-Voltaic Solar Panel under Constant Electric Load," Hindawi Journal of Renewable Energy, volume 2019, p. 9639480, 2019, DOI: 10.1155/2019/9639480.

[17] A. Mehiri, A. Hamid and S. Almazrouei, "The Effect of Shading with Different PV Array Configurations on the Grid-Connected PV System,” 2017 International Renewable and Sustainable Energy Conference (IRSEC), 2017, pp. 1-6, DOI: 10.1109/IRSEC.2017.8477420.

[18] Fekkak, B., Menaa, M., and Boussahoua, B, "Control of transformerless grid-connected PV system using average models of power electronics converters with MATLAB/Simulink," Solar Energy, vol. 173, pp. 804-813, 2018, DOI: 10.1016/j.solener.2018.08.012.

[19] Ali Q. Al-Shetwi and Muhamad Zahim Sujod, "Modeling and Dynamics Study of Large Scale PV System Connected Malaysian Grid under Different Fault Conditions," 2016 International Conference on Advances in Electrical, Electronic and Systems Engineering (ICAEES), 2016, pp. 488-494, DOI: 10.1109/ICAEES.2016.7888094.

[20] T. Laagoubi, M. Bouzi and Mohamed Benchagra, "MPPT power factor control for grid connected PV systems with fuzzy logic controllers, “International Journal of Power Electronics and Drive System (IJPEDS), vol. 9, no. 1, pp. 105-113, 2018, DOI: 10.11591/ijpeds.v9.i1.pp105-113.

[21] S. Pareek and R. Dahiya, "Simulation and performance analysis of individual module to address partial shading cum parameter variation in large photovoltaic fields," J. Energy Power Sources, vol. 2, no. 3, pp. 99-104, 2015.

[22] A. Yahya, H. El Fadil, M. Oulcaid, "Output feedback nonlinear control of three-phase grid-connected PV generator," International Journal of Power Electronics and Drive System (IJPEDS), vol. 10, no. 1, pp. 137-150, 2019, DOI: 10.11591/ijpeds.v10.i1.pp137-150.

[23] D.D. Nguyen and G. Fujita, "Observer-based decoupling power control for frequency modulated Dual-ActiveBridge converter," 2016 IEEE 8th International Power Electronics and Motion Control Conference (IPEMCECCE Asia), 2016, pp. 754-760, DOI: 10.1109/IPEMC.2016.7512380.

[24] M. Carrasco and F. Mancilla-David, "Maximum power point tracking algorithms for single-stage photovoltaic power plants under time-varying reactive power injection," Solar Energy, vol. 132, pp. 321-331, 2016, DOI: 10.1016/j.solener.2016.03.023.

[25] Z. Wu, D.W. Gao, H. Zhang, S. Yan, and X. Wang, "Coordinated Control Strategy of Battery Energy Storage System and PMSG-WTG to Enhance System Frequency Regulation Capability," IEEE Transactions on Sustainable Energy, vol. 8, no. 3, pp. 1330-1343, 2017, DOI: 10.1109/TSTE.2017.2679716.

[26] H. Belmili, MF. Almi, B. Bendib, and S. Bolouma, "A Computer program development for sizing stand-alone photovoltaic-wind hybrid systems," Energy Procedia, vol. 36, pp. 546-557, 2013, DOI: 10.1016/j.egypro.2013.07.063.

[27] R. Ben Ali, H. Schulte, and A. Mami, "Modeling and Simulation of a small Wind Turbine system based on PMSG generator," 2017 Evolving and Adaptive Intelligent Systems (EAIS), 2017, pp. 1-6, DOI: 10.1109/EAIS.2017.7954833.

[28] C. Ed-dahmani, H. Mahmoudi, I. Rais, and A. Bakouri, "Dynamic Simulation of PMSG Wind Turbine on ZedBoard FPGA," 2019 International Conference on Wireless Technologies, Embedded and Intelligent Systems (WITS), 2019, pp. 1-6, DOI: 10.1109/WITS.2019.8723678.

[29] S. Henninger, J. Jaeger, "Advanced classification of converter control concepts for integration in electrical power systems," Electrical Power and Energy Systems, vol. 123, p. 106210, 2020, DOI: 10.1016/j.ijepes.2020.106210.

[30] 31M. Mansour, M.N. Mansouri, S. Bendoukhaa, M.F. Mimouni, "A grid connected variable speed wind generator driving a fuzzy controlled PMSG and associated to flywheel energy storage system," Electric Power Systems Research, vol. 180, p. 106137, 2020, DOI: 10.1016/j.epsr.2019.106137.

[31] A.M. Eltamaly, A.I. Alolah, H.M. Farh, "Maximum power extraction from utility-interfaced wind turbines," in New Developments in Renewable Energy, InTech, 2013, DOI: 10.5772/54675. 


\section{BIOGRAPHIES OF AUTHORS}

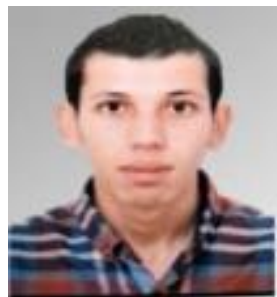

Hakim AZOUG, PhD student in renewable energies at the University of Science and Technology Houari Boumedienne -Unit for Development of Solar Equipment where the subject is «Design and Automation of a PV/wind/diesel hybrid mini-power plant with energy storage». He received his baccalaureate diploma in Experimental Science in 2010. In 2013, he received his Bachelor's degree in Energy Mechanics at USTHB, then his Master's degree in Renewable Energies in 2015. In 2017, he held the position of Study Engineer in Renewable Energy at Amimer Energy SPA and in 2018, he became the head of the «renewable energy» section. Recently, he worked with various C\&I projects across Algeria. Technical manager for the construction of wo photovoltaic power plants with hybrid control system with the existing diesel power plants (12MWC) in Algeria, where 10MWc in Bordj Badji Mokhtar and 02MWc in Timiaouine.

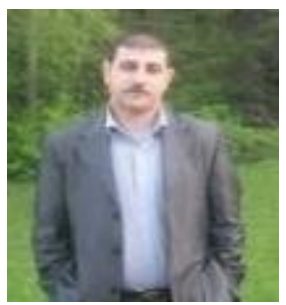

Dr. Hocine Belmili is a Senior Research in Electronic Engineering. Obtained the state engineer degree in Electronic Engineering from frères Mentouri University of Constantine in 2001, and MSc degree from Ferhat Abbas Sétif1 University in 2004. Hold the PhD degree in Electronic engineering from National Polytechnic School (Algeria), in 2012. In 2014, he received the HdR degree from Saad Dahlab University of Blida. In 2019 he had promotion on Senior Research degree. the Areas of interest are renewable energy systems, distributed systems, the application of advanced methods in control and improvement in energy conversion systems, the energy management and faults detection in Hybrid systems. Conduct several research projects in renewable energy. He has supervised several LMD doctors, Engineers and Masters students. He is with the Unit of Development of Solar Equipments / Renewable Energy Center, ALGERIA, from 2005 until now. Serves as reviewer with many International Journals (Scopus and Thomson routers). Author of many publications, book chapters and papers with lecture committee. 